\title{
TWO DIMENSIONAL SWITCHED BEAM ANTENNA BASED ON CASCADED BUTLER MATRIX BEAMFORMING NETWORK
}

\author{
S. I. Orakwue ${ }^{1, *}$ and R. Ngah² \\ 1, Department of Electrical Electronic Engineering, Univ. OF PorT-Harcourt, Rivers State, NIGERIA \\ 2, Wireless COMMUNiCATION CENTRE, UNIVERSITI TEKNOLOGi MALAYSiA (UTM), 81310 SKUDAI, JOHOR, MALAYSIA \\ E-mail addresses: ${ }^{1}$ stella.orakwue@uniport.edu.ng, ${ }^{2}$ razalingah@fke.utm.my
}

\begin{abstract}
This paper presents a low cost, two dimensional (2-D) millimetre wave switched-beam array antenna attained by feeding a planar array antenna with a cascaded $4 \times 4$ Butler matrix (BM) beam forming network (BFN). To minimise the surface current, ensure low cost and ease fabrication, a single layer has been implemented. The prototype is fabricated and measured results presented. According to the results, the maximum beam scanning of from $-41^{\circ}$ to +420 , and a maximum antenna gain of $13.8 \mathrm{dBi}$ are obtained in the $x-z$ plane. While the maximum beam scanning of from $-43^{\circ}$ to $+41^{\circ}$ and the maximum antenna gain of $13.7 \mathrm{dBi}$ are realized in the $y-z$ plane. With a single pole multiple throw switches, switching the various matrix terminals on the BM in the horizontal plane gives the beams in the $x-z$ plane, while switching the BM in the vertical plane gives the beams in the $y-z$ plane. All experimental and numerical results are in good agreement which can be practically used for fifth generation (5G) wireless systems.
\end{abstract}

Keywords: Cascaded Butler matrix, Beamforming Network, switched-beam antenna, $5 G$

\section{INTRODUCTION}

Switched beam smart antenna (SBSA) has attracted great interest in modern wireless communication due to its ease of implementation and flexibility for use in multiple applications [1]. The performance of a SBSA depends on the design of beam forming network (BFN) that provides constant beam directions. Many BFN configurations have been designed, such as Blass Matrix [2], Rotmans Lens [3], and Butler Matrix (BM). The SBSA studied using BM BFN as the basic component has received so much attention [4-9] due to its simplicity and ease of implementations and has been chosen for this research work. It can support beam switching operation and allows 1-D switching [4, 10 -12] at $\pm 45^{\circ}$ and $\pm 135^{\circ}$. It is completely passive, minimising front-end power consumption.

Planar arrays with 2-D beam switching capabilities are highly desirable for $5 \mathrm{G}$ networks aiming to operate at millimetre waves. Several 2-D beam switching array antennas based on modified BM BFN have been proposed [13-16]. Nevertheless, the complex realisation and large size of most of these designs are not suitable at $28 \mathrm{GHz}$ frequency band. For instance, [14] utilises twenty-two crossovers and twelve 3-dB branch line couplers (BLCs) to achieve 2-D beam switching at $60 \mathrm{GHz}$, while [17] used two $4 \times 4 \mathrm{BM}$ and one $8 \times 8 \mathrm{BM}$ to achieve 2-D at $2.45 \mathrm{GHz}$. These would be outrageous if applied to $28 \mathrm{GHz}$ frequency. In [13] and [18] four orthogonal beams were realised at the two principal planes by integrating BLCs on the multi-layer substrate. Nevertheless, the multi-layered substrate resulted in 2-D beam switching array antenna with high-profile, more complexity and high cost.

In this paper, a 2-D switched-beam antenna based on $4 \times 4$ planar design BM BFN has been presented. The approach of lateral cascading of two BM BFN is applied to achieve 2-D switched-beam array antenna in the two principal planes. Firstly, a switched-beam array antenna at $28 \mathrm{GHz}$ for a $5 \mathrm{G}$ wireless system based on BM BFN was designed and published in [12]. Then based on the fact that antenna array geometry 
considerably affects the main lobe characteristics and the beam scanning capabilities of the array [19], lateral cascading of two $4 \times 4$ BM BFN is applied to achieve a simple and compact 2-D beam switching array antenna on a single substrate. Furthermore, input ports are extended to eliminate the ports proximity problem of [11] and realise a switched-beam antenna that is simple to integrate with other electronic components via a connector.

\section{TWO DIMENSIONAL SWITCHED BEAM ARRAY ANTENNA DESIGN}

The layout of the proposed design is shown in Figure 1. It consists of two $4 \times 4 \mathrm{BM}$ and $4 \times 4$ array antenna connected with equal length and equal width transmission lines. The BM is exactly the one discussed in [12].

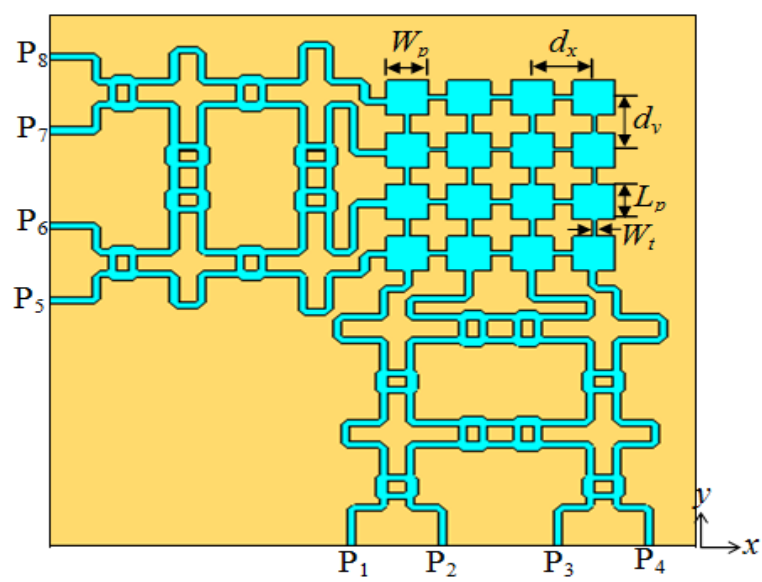

Figure 1: Geometry of the proposed 2-D beam switching array antenna

The dimension of the proposed 2-D array antenna is $57.81 \times 59.56 \times 0.254 \mathrm{~mm}^{3}$. The antenna is connected to a $50 \Omega, 2.9 \mathrm{~mm}$ edge K-connector for signal transmission. The cascaded BM has eight excitation ports. When fed by any of P1 to P4, it produces beams that are orthogonal along the horizontal axis at angles $-80^{\circ}, 430,-410$ and 170 ; but when fed by P5 to P8, the beams are scanned along the elevation axis at $-12{ }^{\circ}, 42^{\circ},-43^{\circ}$ and $16^{\circ}$. The effect of the width of the connecting transmission lines was studied, and this showed a significant change in the antenna performance. The final fabrication was based on the optimum parameters obtained through parametric studies. Simulated and measured performance results are presented to verify the design. The proposed 2-D is uniplanar and, hence, leads to low-cost manufacturing and integration with $28 \mathrm{GHz}$ radios. The network produces eight 2-D beam states and demonstrates beamforming capability across the operation band.

\subsection{Bandwidth Optimization of the Proposed 2- D Beam Switching Array Antenna}

A parametric study is conducted to evaluate the effect of the antenna parameters on antenna performance, by the process of parametric sweep in CST MWS environment and presented. The study is based on the width of the connecting transmission lines $\left(W_{t}\right)$ between the patch. A simulation was done using different width size ranging from $0.5 \mathrm{~mm}$ to $0.85 \mathrm{~mm}$. The study revealed that the width of the transmission lines connecting the patch has a significant effect on the performance of the antenna. It can be seen from Table 1 that $W_{t}$ affects the return loss significantly. By increasing $W_{t}$, the matching of the frequency band (from $26 \mathrm{GHz}$ to $31 \mathrm{GHz}$ ) is considerably improved. This phenomenon is because the size of the transmission line can influence the coupling between the patch. When the $W t$ is $0.85 \mathrm{~mm}$, better matching is achieved and the widest bandwidth of the proposed antenna is realized followed by when $W t$ is $0.74 \mathrm{~mm}$. Table 2 represents the lower frequency $\left(F_{L}\right)$ and high frequency $\left(\mathrm{FH}_{\mathrm{H}}\right)$ of $\mathrm{S}_{\mathrm{jj}}$ in terms of $10 \mathrm{~dB}$ return loss criteria.

Table 1: Result comparison of different values of Wt

\begin{tabular}{lllllll}
\hline & \multicolumn{2}{l}{$W t=0.5 \mathrm{~mm}$} & \multicolumn{2}{c}{$W t=0.74 \mathrm{~mm}$} & \multicolumn{2}{c}{$W t=0.85$} \\
\cline { 2 - 7 } & $\mathrm{FL}$ & $\mathrm{FH}_{\mathrm{L}}$ & $\mathrm{FL}$ & $\mathrm{FH}_{\mathrm{H}}$ & $\mathrm{FL}$ & $\mathrm{FH}_{H}$ \\
\hline $\mathrm{S}_{11}(\mathrm{GHz})$ & 26.97 & 30.75 & 26.02 & 30.72 & 25.58 & 30.57 \\
$\mathrm{~S}_{22}$ & 26.47 & 30.75 & 25.9 & 30.77 & 26 & 31.04 \\
$\mathrm{~S}_{33}$ & 27 & 30.7 & 25.9 & 30.72 & 26.7 & 32 \\
$\mathrm{~S}_{44}$ & 27 & 30.7 & $26.06,30.1$ & $29.8,30.7$ & 25.58 & 30.96 \\
$\mathrm{~S}_{55}$ & 26.94 & 30.69 & 26.25 & 30.76 & 25.58 & 30.69 \\
$\mathrm{~S}_{66}$ & 26.64 & 30.73 & 26.02 & 30.79 & 26.6 & 32 \\
$\mathrm{~S}_{77}$ & 26.67 & 30.69 & 26.18 & 30.71 & 25.86 & 30.9 \\
$\mathrm{~S}_{88}$ & 26.75 & 30.68 & 26.17 & 30.76 & 25.03 & 30.7 \\
\hline
\end{tabular}


The effects of $W t$ on the gain and beam positions are tabulated in Table 2. From the table, the antenna performance is considered better when $W_{t}$ is $0.74 \mathrm{~mm}$. Considering $x z$-plane, $W_{t}=0.74 \mathrm{~mm}$ has the highest beam position of $43^{\circ}$ in port 2 and lowest of $-41^{\circ}$ in port 3. In other words, it can scan from $-41^{\circ}$ to $43^{\circ}$ in the $x z$-plane. Then, in the $y z$-plane, with $W_{t}=0.74$ $\mathrm{mm}$, the highest beam pointing position is $42^{\circ}$ at port 6 , while the lowest is $-43^{\circ}$ at port 7; meaning a beam scanning of from $-43^{\circ}$ to $42^{\circ}$. When $W_{t}=0.85 \mathrm{~mm}$ is considered, beam scanning of from -140 to $33^{\circ}$ is achieved in the $x z$-plane (the highest beam pointing position is $33^{\circ}$ at port 3 , while the lowest is -140 at port 4) and for the $y z$-plane, beam scanning of from $18^{\circ}$ to 60 is achieved (the highest beam pointing angle of 60 at port 6 , while the lowest is $-18^{\circ}$ at port 8 ). $W_{t}$ $=0.5$ has good beam scanning capability in the $y z$ plane, from -490 to 410 , with the highest beam pointing angle of $41^{\circ}$ at port 6 , while the lowest is $49 \circ$ at port 5. However, when $x z$-plane is considered, the realized beam scanning is from -160 to 70 , with the highest beam pointing angle of 70 at port 2 , and the lowest of $-16^{\circ}$ at port 3.

Table 2 : Antenna performance due to different values of Wt

\begin{tabular}{|l|l|l|l|l|l|l|l|l|l|}
\hline \multirow{2}{*}{$W_{t}(\mathrm{~mm})$} & \multirow{2}{*}{ Parameters } & \multicolumn{3}{|l|}{ Switching Angles in $x z$-plane } & \multicolumn{3}{|l|}{ Switching Angles in $y z$-plane } \\
\cline { 3 - 10 } & & P1 & P 2 & P 3 & P 4 & P 5 & P 6 & P 7 & P 8 \\
\hline \multirow{3}{*}{0.5} & Realized Gain(dB) & 14.4 & 13.0 & 12.3 & 14.6 & 13.3 & 11.5 & 12.4 & 14.7 \\
\cline { 2 - 11 } & Switching angle (deg) & -9.0 & 7.0 & -16.0 & 1 & -49.0 & 41 & -31 & 17 \\
\cline { 2 - 10 } & HPBW (deg) & 29.5 & 59.7 & 59.2 & 35.5 & 29.3 & 68.6 & 67.9 & 30.7 \\
\hline \multirow{3}{*}{0.74} & Realized Gain (dB) & 14.4 & 12.6 & 12.7 & 13.8 & 13.9 & 12.1 & 12.1 & 14.2 \\
\cline { 2 - 10 } & Switching angle (deg) & -8 & 43 & -41 & 17 & -12 & 42 & -43.0 & 16.0 \\
\cline { 2 - 10 } & HPBW (deg) & 22.7 & 31.7 & 36.4 & 28.5 & 29.0 & 32.3 & 30.9 & 23.2 \\
\hline \multirow{3}{*}{0.85} & Realized Gain (dB) & 14.1 & 12.5 & 12.9 & 13.3 & 14.1 & 12.6 & 12.9 & 13.8 \\
\cline { 2 - 10 } & Switching angle (deg) & 10.0 & -2.0 & 33.0 & -14 & -7.0 & -1.0 & 6.0 & -18 \\
\cline { 2 - 9 } & HPBW (deg) & 27.1 & 12.2 & 28.1 & 32.8 & 28.6 & 12.7 & 32.5 & 18.3 \\
\hline
\end{tabular}

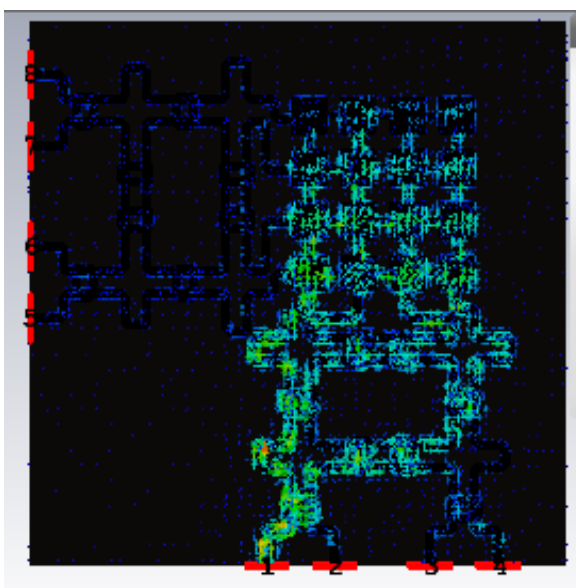

(a)
When the gain is considered, all the array gains ( $P 1$ to P8) are greater than $12.5 \mathrm{~dB}$ when $W_{t}$ is $0.85 \mathrm{~mm}$, and greater than $12.1 \mathrm{~dB}$ when $W_{t}$ is $0.74 \mathrm{~mm}$. Although $W_{t}=0.85 \mathrm{~mm}$ has the advantage of higher gain and bandwidth, in most of the ports, $W_{t}=0.74 \mathrm{~mm}$ is considered as the optimum dimension based on the realized beam position (scanning angle) performance. A stable bandwidth of from $26.8 \mathrm{GHz}$ to $30.7 \mathrm{GHz}$ for a $10 \mathrm{~dB}$ return loss criteria is achieved across the band of operation.

The isolation between the ports can also be seen from Figure 2 that shows the current flow in the proposed structure. When a particular port is fed with $28 \mathrm{GHz}$ signal, the signal travel down to drive the array antenna at the output blocking the signals from other ports as expected with the crossover successfully coupling the signal across the branches. This implies that the couplings between the ports are minimal. Therefore, a small amount of current will be coupled to the other ports, without changing its input impedance if only one port is fed.

Figure 2: The isolation between the ports: (a) Port 1, (b) Port 5

logarithmic -

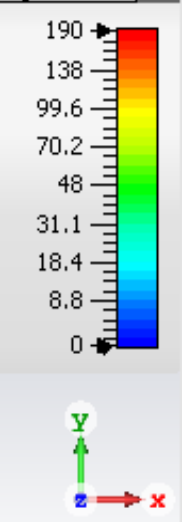

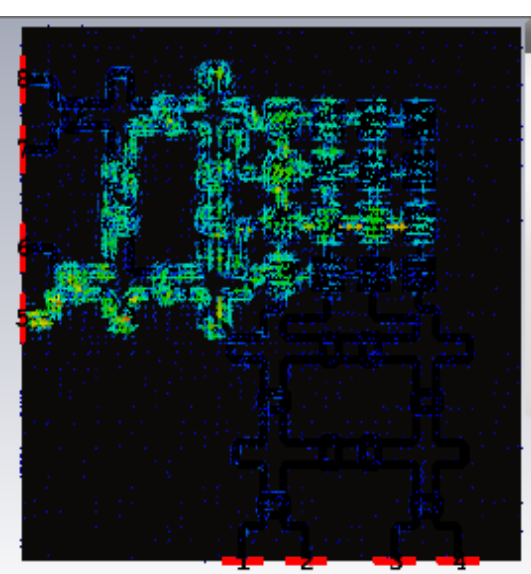

(b)

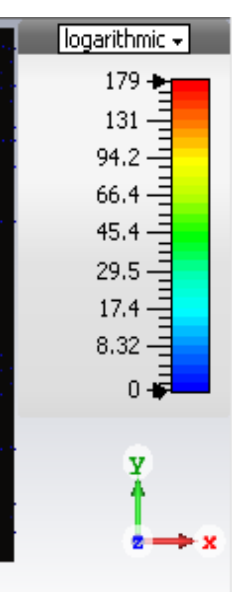

1 


\subsection{Reflection Coefficient Measurement of the Proposed 2-D Array Antenna}

Fabrication of the prototype and measurement followed once the design is finalized. The fabrication process was carried out at Rep Graphic Sdn. Bhd. Selangor, Malaysia. Figure 3 shows the prototype of the antenna with a substrate size of $59.56 \mathrm{~mm} \times 57.81 \mathrm{~mm} \times 0.254$ $\mathrm{mm}$. A $2.92 \mathrm{~mm}$ receptacle PCB edge mount connectors with PTFE dielectric material as feed insulator was used. The $2.92 \mathrm{~mm}$ connectors are $50 \Omega$ precision connectors designed with excellent characteristics over the full frequency range up to $40 \mathrm{GHz}$. The centre pin of the $2.92 \mathrm{~mm} \mathrm{~K}$ connector extending $0.6 \mathrm{~mm}$ was soldered to the top plate at the feed point, as seen in Figure 3, and the edge soldered to the ground plane. The soldering of the conductor is the most difficult part as good soldering skills are needed because the centre pin is too small ( $0.6 \mathrm{~mm}$ long) in order to have good measurement results.

Measurement of reflection coefficient was carried out using KEYSIGHT PNA-L Network Analyser. The measurement setup was as shown in Figure 4. Before the impedance measurements were performed, the device was calibrated. Also when any port is excited all other ports are terminated with $50 \Omega$ terminator. All the ports are measured and the measurement results compared with the simulated results by plotting the graph as shown in Figure 5. The figures show a comparison between measured and simulated results. The measured reflection coefficients produced slightly lower than the simulated reflection coefficient. This could be attributed to handling due to the flexibility of the substrate. However, there is an agreement between the measured and simulated reflection coefficients. The measured reflection coefficient plots showed good impedance matching of all the ports across the band of interest; the $28 \mathrm{GHz}$ proposed for future $5 \mathrm{G}$ wireless communication. When compared with the 2-D antenna array of [8], the proposed antenna is better in terms of gain and cost since three-layered design means an increase in cost and complexity.

\subsection{Radiation Pattern Measurement of the Proposed 2-D Array Antenna}

The radiation patterns are measured in an indoor anechoic chamber using a near-field measurement system at a resonant frequency of $28 \mathrm{GHz}$. The measured radiation pattern shown here is plotted and normalised to $0^{\circ}$, as shown in Figure 6 . There is a better agreement between the measurements and the simulations radiation patterns of ports 1,47 and 8 . Other ports demonstrate many variations which could be attributed to measurement errors. Moreover, the difference between the connector pin diameter ( 0.76 $\mathrm{mm})$ and the substrate diameter $(0.254 \mathrm{~mm})$ was not considered in the simulation.

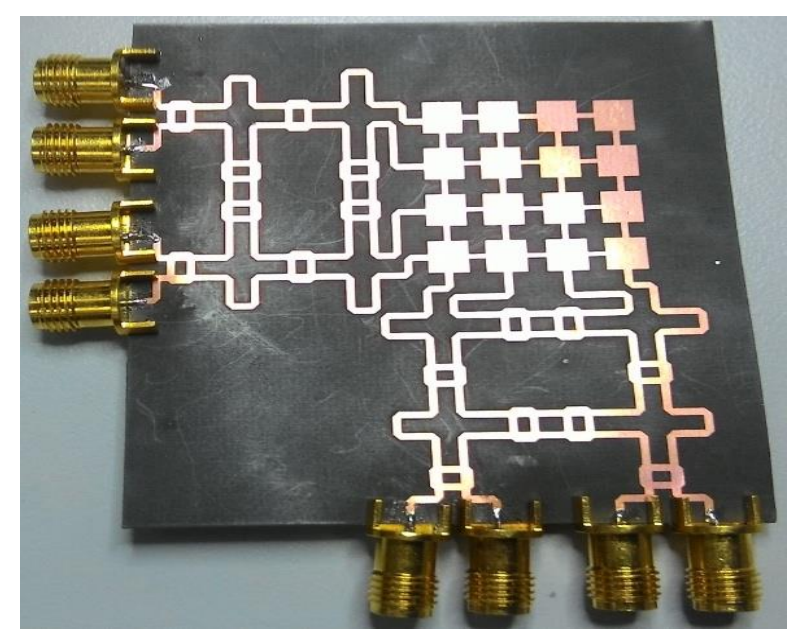

Figure 3: The fabricated prototype of the proposed antenna
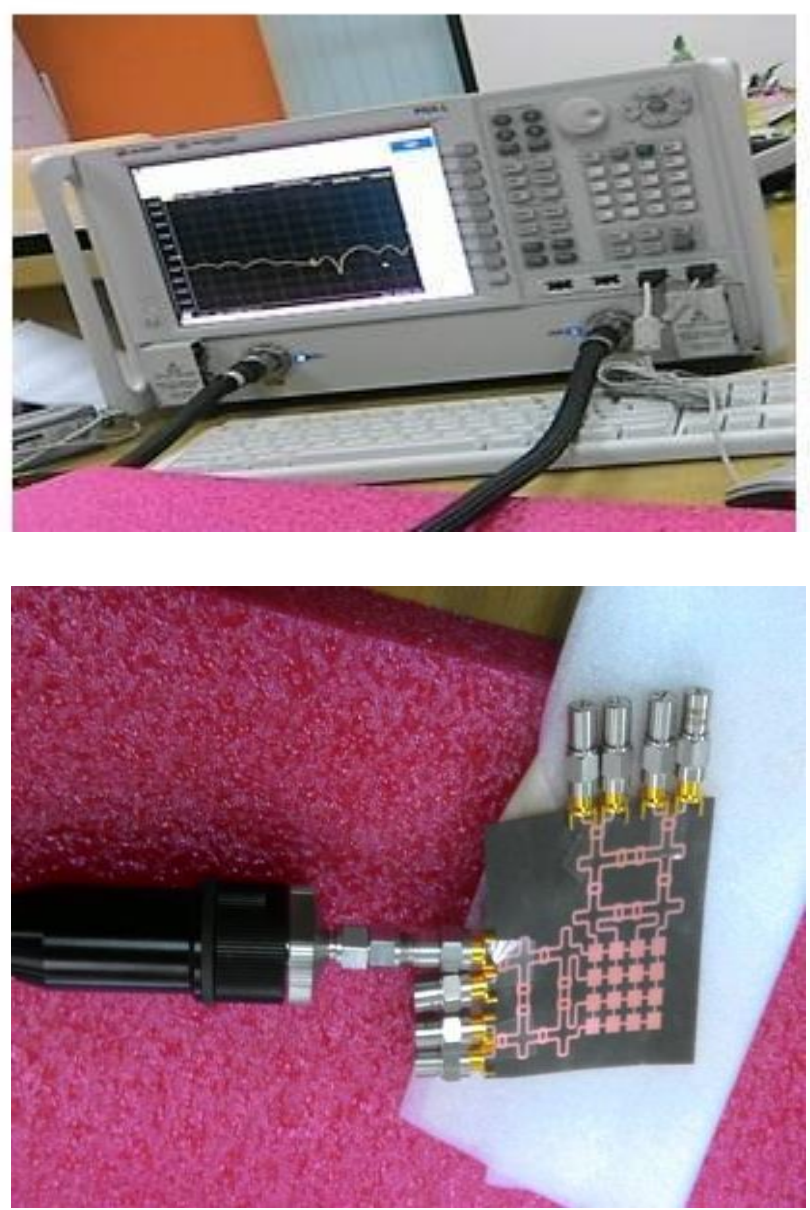

Figure 4: The S-parameter measurement set-up 


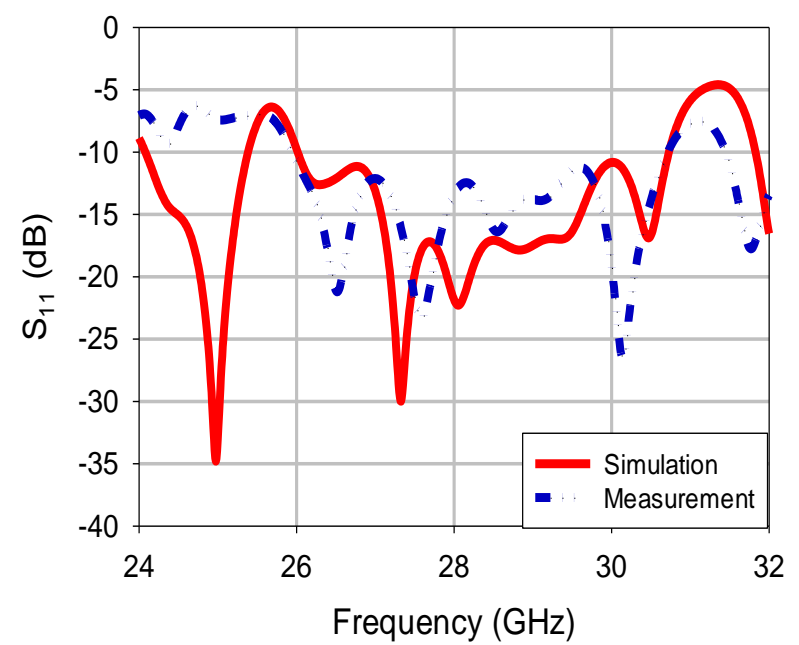

(a) $\mathrm{P} 1$

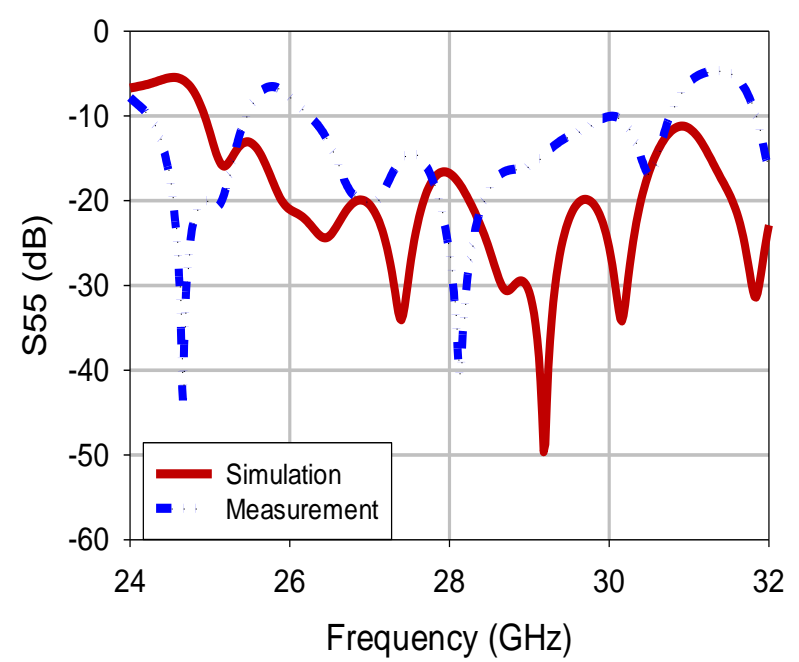

(c) P5

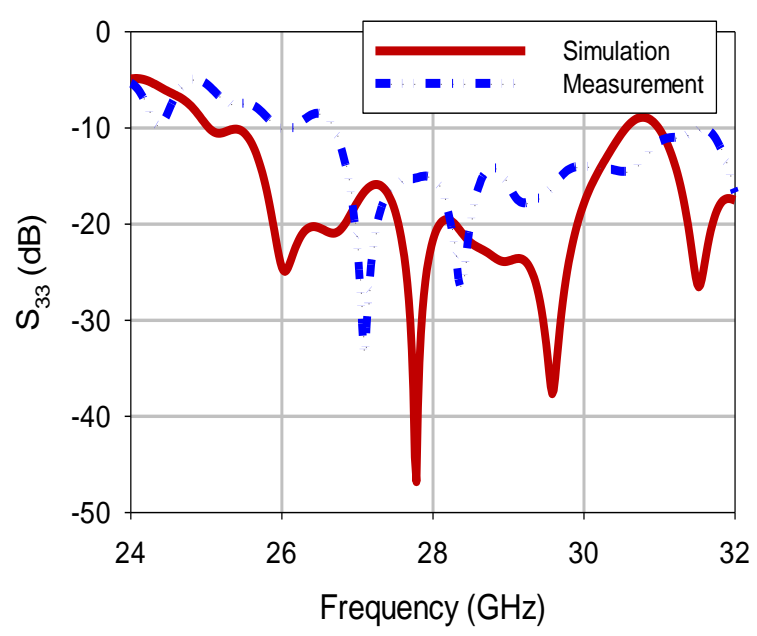

(b) P3

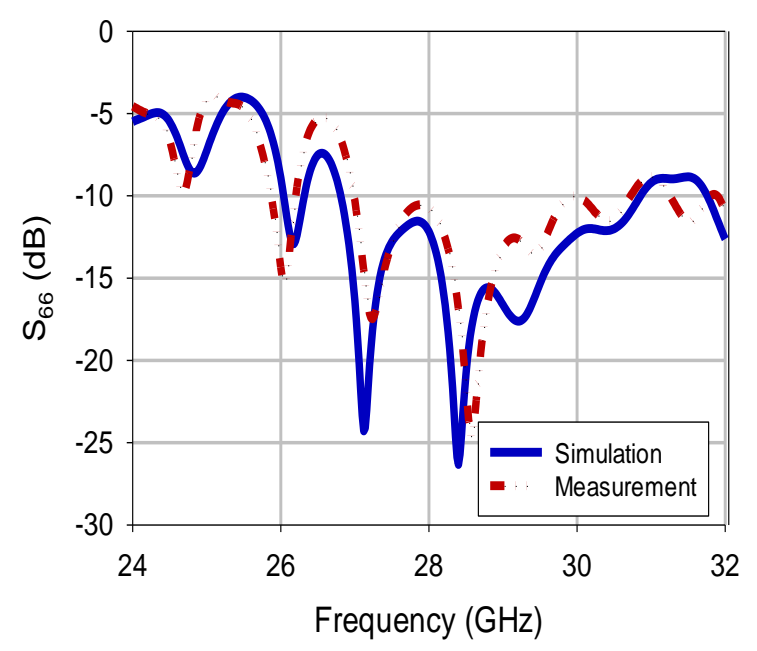

(d) P7

Figure 5: The comparison of simulation and measurement return loss of the proposed 2-D beam switching array antenna.

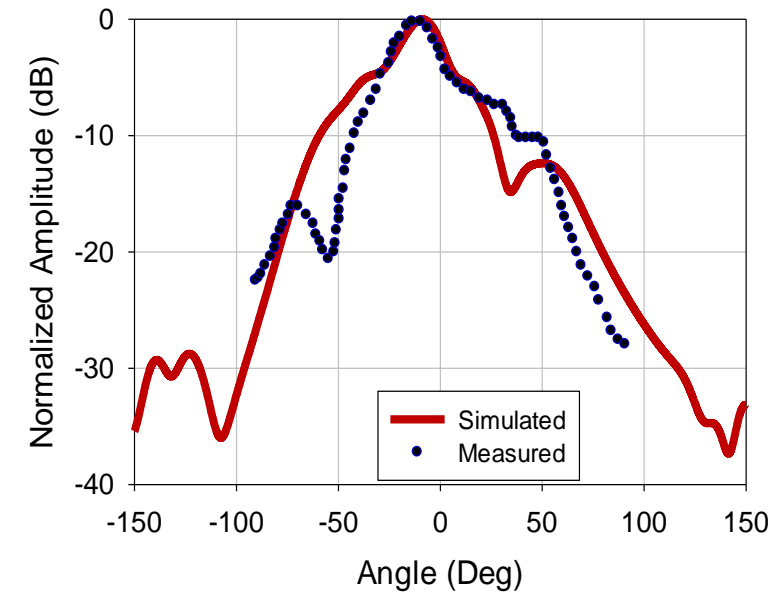

(a) P1

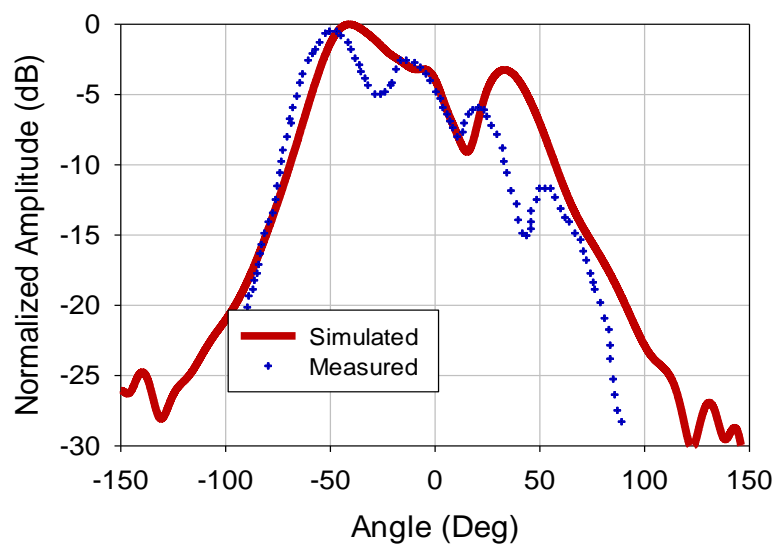

(b) P3 


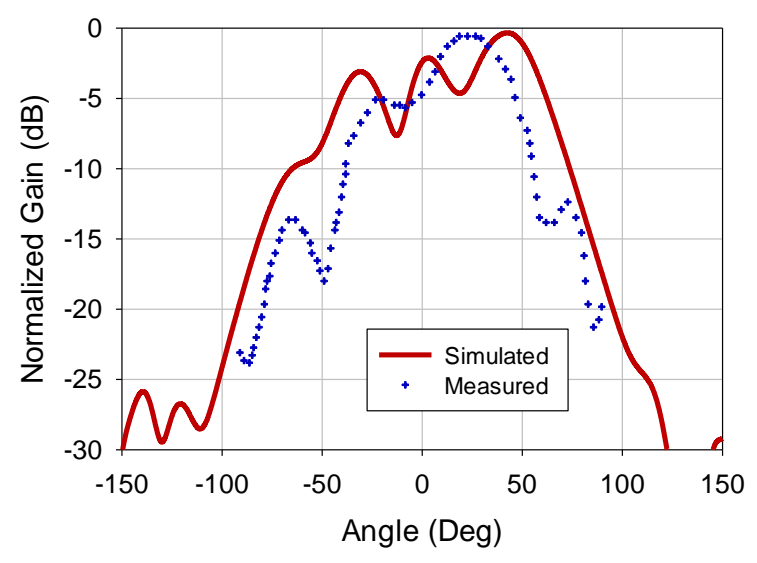

(c) P5

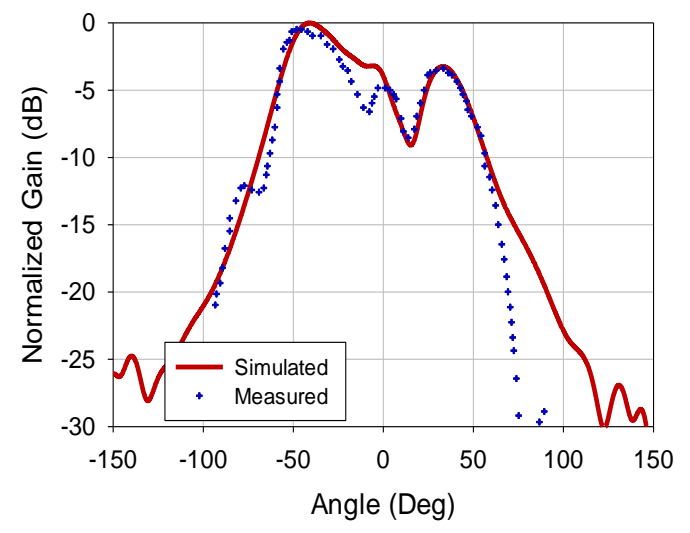

(d) P7

Figure 6: The comparison of simulation and measurement radiation pattern of the ports:

\section{CONCLUSION}

The design, simulation and measurement of the proposed 2-D switched-beam array antenna on $4 \times 4$ $\mathrm{BM}$ has been presented. The design started with the design of BLC, followed by the design of a $4 \times 4$ BM and a 1-D switched-beam array antenna on $4 \times 4$ BM [12]. Then, two of the BM BFN are laterally cascaded to realize the 2-D array antenna. The performances of all the designed devices are verified by measurement. The proposed 2-D array antenna produces eight orthogonal beams and can scan in the two principal planes.

\section{REFERENCES}

[1] Mok, .S-G., Jung, .C-W., Ha, .S-J., Kim, .Y. "Switchable beam pattern antenna for wireless communication devices", Proceedings of the IEEE International Symposium on Antennas and Propagation (APSURSI), 2011, 1308-1310.

[2] Casini, .F., Gatti, .R.V., Marcaccioli, .L., Sorrentino, .R. "A novel design method for Blass matrix beam-forming networks", Proceedings of the IEEE Radar Conference, (EuRAD European), 2007, 232-235.

[3] Cheng, .Y]., Hong, .W., Wu, .K., Kuai, .ZQ., Yu, .C., Chen, .JX., Zhou, .JY., Tang, .HJ. "Substrate integrated waveguide (SIW) Rotman lens and its Ka-band multibeam array antenna applications", IEEE Transactions on Antennas and Propagation, 2008, 56(8): 2504-2513.

[4] Choi, .W., Park, .K., Kim, .Y., Kim, .K., Kwon, .Y. "A-Band Switched Beam-Forming Antenna Module Using Absorptive Switch Integrated With 44 Butler Matrix in 0.13-CMOS", IEEE Transactions on Microwave Theory and Techniques, 2010, 58 (12): 4052-4059.
[5] Aribi, .T., Naser-Moghadasi, .M., Sadeghzadeh, .R. "Broadband circularly polarized beamsteering antenna array for wireless applications", Microwave and Optical Technology Letters, 2014, 56(12): 2813-2816.

[6] Liu, .C., Xiao, .S., Guo, ,Y-X., Tang, .M-C., Bai, .Y-Y., Wang, .B-Z. "Circularly polarized beamsteering antenna array with butler matrix network", IEEE Antennas and Wireless Propagation Letters, 2011, 10: 1278-1281.

[7] Dall'Omo, .C., Monediere, .T., Jecko, .B., Lamour, .F., Wolk, .I, Elkael, .M. "Design and realization of a $4 \times 4$ microstrip Butler matrix without any crossing in millimeter waves", Microwave and Optical Technology Letters., 2003, 38(6): 462465.

[8] Cheng, .Y]., Hong, .W., Wu, .K. "Millimeter-wave multibeam antenna based on eight-port hybrid", IEEE Microwave and Wireless Components Letters, 2009, 19(4): 212-214.

[9] Kaminski, .P., Wincza, .K., Gruszczynski, .S. "Switched-beam antenna array with broadside beam fed by modified butler matrix for radar receiver application", Microwave and Optical Technology Letters, 2014, 56(3): 732-735.

[10] Alreshaid, .AT., Sharawi, .MS., Podilchak, .S., Sarabandi, .K. "Compact millimeter-wave switched-beam antenna arrays for short range communications", Microwave and Optical Technology Letters, 2016, 58 (8), pp. 19171921 ,

[11] Tseng, .C-H., Chen, .C-J., Chu, .T-H."A low-cost 60-GHz switched-beam patch antenna array with Butler matrix network", IEEE Antennas and Wireless Propagation Letters 2008, 7: 432-435.

[12] Orakwue, S. I., \& Ngah, R. (2019). Switchedbeam array antenna at $28 \mathrm{GHz}$ for $5 \mathrm{G}$ wireless 
system based on butler matrix beamforming network. Nigerian Journal of Technology, 38(2), 484-489.

[13] Guntupalli, .A.B., Djerafi, .T., Wu .K. "Twodimensional scanning antenna array driven by integrated waveguide phase shifter", IEEE Transactions on Antennas and Propagation, 2014, 62(3): 1117-1124.

[14] Moulder, .W.F., Khalil, .W., Volakis, .JL. "60-GHz two-dimensionally scanning array employing wideband planar switched beam network", IEEE Antennas and Wireless Propagation Letters, 2010, 9: 818-821.

[15] Guntupalli, .A.B., Wu, .K. "60 GHz circularlypolarized smart antenna system for high throughput two-dimensional scan cognitive radio", Proceedings of the IEEE International Microwave Symposium Digest (IMS), MTT-S, 2013, 1-3.
[16] Guntupalli, .A.B., Wu, .K. "Phase-steered fixed beams in one and two-dimensional scan space for substrate-integrated radar and radio systems at $60 \mathrm{GHz}^{\prime \prime}$, IET Microwaves, Antennas \& Propagation, 2014, 8 (11): 819-828.

[17] Fakoukakis, .F., Diamantis, .S., Orfanides, .A., Kyriacou, .G. "Development of an adaptive and a switched beam smart antenna system for wireless communications", Journal of Electromagnetic Waves and Applications, 2006, 20(3): 399-408.

[18] Guntupalli, .A.B., Wu, .K. "60 GHz circularlypolarized smart antenna system for high throughput two-dimensional scan cognitive radio", Proceedings of the IEEE International Microwave Symposium Digest (IMS), MTT-S, 2013, 1-3.

[19] Saqib, .N-U., Khan, .I. "A Hybrid Antenna Array Design for 3-D Direction of Arrival Estimation", PLOS ONE. 2015; 10(3): e0118914. 